\title{
CORRESPONDENCE
}

\section{Journal Editorials give indication of driving science issues}

By comparing the topics of Editorials published in Nature and Science, we unearthed some fascinating features of the changing policy landscape over the past decade.

To analyse the text of the more than 1,500 Editorials published in Nature and Science between January 2000 and July 2009, we used 'VOSviewer' - a mapping technique that categorizes nonspecialist documents according to the co-occurrence of words (N. J. van Eck and L. Waltman Scientometrics doi:10.1007/ s11192-009-0146-3; 2009). We confirmed the results by manual classification of the contents of a large sample (around $20 \%$ of the Editorials).

Editorial topics over this period covered space and physics (5\%), publication issues (10\%), global political and environmental problems (18\%), biomedical issues (almost 30\%) and science policy issues (39\%). These figures are roughly comparable in Nature and Science, which comes as no surprise as they presumably reflect what the global scientific community considered important at the time. Editorials on climate change, for example, have almost the same prominence in both journals (1 in 10 Editorials).

But there are differences. Nature devotes three times more Editorials to space and physics (and particularly to NASA) than does Science (6\% and $2 \%$, respectively) and twice as many to the National Institutes of Health ( $2 \%$ compared with $1 \%)$. Science pays more attention to developing countries, environmental protection and other global problems.

Science writes more often than Nature about the political influence of science and scientists, whereas Nature writes more about priority setting and the organization of science. It seems that Science, as a learned-society journal, may be more reticent about tackling internal science issues than the independent journal Nature.

Cathelijn J. F. Waaijer, Cornelis A. van Bochove, Nees Jan van Eck, Centre for Science and Technology Studies, Leiden University, the Netherlands e-mail:cbochove@cwts.nl

\section{Let interdisciplinary research begin in undergraduate years}

The UK Higher Education Academy's 2009 report 'Developing undergraduate research and inquiry' (see go.nature.com/WtYWpk) encourages greater student participation in departmental research. This is a welcome cultural shift from the traditional route of studying published research papers and undertaking research projects in separate undergraduate modules. It could also provide an ideal opportunity for mainstreaming interdisciplinary research in undergraduate science education.

This would mean going beyond the occasional, often experimental, crossdepartmental module. Most undergraduate science courses can be designed and delivered so that subject-based theories are taught alongside research results arising from their interdisciplinary applications. Courses aimed at developing key research skills, such as literature review and communication, would be all the more useful if they embraced interdisciplinary research content.

Students engage in the research process by tackling research problems based on published papers. The importance of interdisciplinary research through analysis and critical comparison of original published work cannot be overstated, given the predominant use of subjectbased textbooks in today's undergraduate science education.
Making the transition to postgraduate research from undergraduate modules is not easy and is not necessarily successful at present. Earlier engagement with interdisciplinary research methodologies and results is likely to reveal fresh horizons to the next generation of scientists.

C. H. Tong Department of Earth and Planetary Sciences, Birkbeck, University of London, Malet Street, London WC1E 7HX, UK e-mail: vincent.tong@ucl.ac.uk

\section{Spanish cuts could do lasting damage to biomedical research}

You were right to criticize the situation faced by basic research in your Editorial on Spain's investment in science (Nature 462, 137-138; 2009).

Despite our executive's alleged commitment to research and development, the reality is a drastic reduction in the science budget for 2010 .

Genoma España, the public foundation for the development of genomics and proteomics research in Spain, is an example. If the government $U$-turn goes ahead, the organization's budget for 2010 will be cut by $40 \%$. In response, the newly appointed managers have decided to devote the entire budget to technologytransfer policies. This step will compromise support for some of Spain's most important institutions - namely, our DNA bank, the National Genotyping Centre and the country's institutes for bioinformatics and proteomics. This harsh policy reversal will cause dramatic and lasting damage to Spanish biomedical research.

ProteoRed, the Spanish national institute for proteomics, is a case in point. Strategic funding by Genoma España has enabled proteomics facilities to provide top-notch services, allowing scientists to participate in prestigious international projects. History will condemn the loss of this timely investment in Spanish biotechnology.

Juan Pablo Albar ProteoRed, Centro Nacional de Biotecnologla/CSIC, UAM Campus Cantoblanco, Darwin 3, Madrid 28049, Spain e-mail:jpalbar@proteored.org

\section{To make progress we must remember and learn from the past}

Indira Samarasekera calls for more effective collaboration among universities, governments and the private sector in her Opinion article (Nature 462, 160-161; 2009). Her arguments are not new - they have been central to research policy and sociology of science debates for more than 60 years (see, for example, V. Bush Science: The Endless Frontier US Office of Scientific Research and Development; 1945).

Today's tools for efficient literature searches are on hand to prevent old debates from continually resurfacing. Keeping track of developing ideas by conscientious referencing is essential. Then, to act upon what has been learned, we must remember. As scientists, we remember collectively through cited publications.

This particular debate is important because it challenges the very core of science by discussing how and why knowledge is made, used and mobilized. We should be drawing on the valuable insights from previous decades in our attempts to set a new social contract for science.

Bart Penders Radboud University Nijmegen, Centre for Society and Genomics, 6500 GL Nijmegen, the Netherlands e-mail:b.penders@science.ru.nl Niki Vermeulen Department of Social Studies of Science, University of Vienna, Vienna, Austria

John N. Parker National Center for Ecological Analysis and Synthesis, Santa Barbara, California 93101, USA 